\title{
Neurophysiological Manifestations of Auditory Hypersensitivity Correlate with Daily Life Experiences
}

\author{
Sharon Zlotnik ${ }^{1}$, Joseph Attias ${ }^{2}$, Hillel Pratt ${ }^{3}$, Batya Engel-Yeger ${ }^{4}$ \\ ${ }^{1}$ Department of Occupational Therapy, Faculty of Social Welfare \& Health Sciences, University of Haifa, Haifa, Israel \\ ${ }^{2}$ Department of Communication Sciences and Disorders, Faculty of Social Welfare \& Health Sciences, University of Haifa, \\ Haifa, Israel \\ ${ }^{3}$ Evoked Potentials Laboratory, Technion-Israel Institute of Technology, Haifa, Israel \\ ${ }^{4}$ Department of Occupational Therapy, Faculty of Social Welfare \& Health Sciences, University of Haifa, Haifa, Israel \\ Email: sharonzlotnik5@gmail.com
}

How to cite this paper: Zlotnik, S., Attias, J., Pratt, H. and Engel-Yeger, B. (2018) Neurophysiological Manifestations of Auditory Hypersensitivity Correlate with Daily Life Experiences. Neuroscience \& Medicine, 9, 29-45.

https://doi.org/10.4236/nm.2018.91005

Received: February 13, 2018

Accepted: March 20, 2018

Published: March 23, 2018

Copyright $\odot 2018$ by authors and Scientific Research Publishing Inc. This work is licensed under the Creative Commons Attribution International License (CC BY 4.0).

http://creativecommons.org/licenses/by/4.0/

\section{(c) (i) Open Access}

\begin{abstract}
Background: This study aimed to compare the neurophysiological responses to sound in adults with hypersensitivity compared to adults without hypersensitivity, and correlate the daily-life experiences to the neurophysiological manifestations. Material and Methods: The Adolescent/Adult Sensory Profile (AASP) was administered to 27 adults, separated by their cut-off scores. Differences in neurophysiological responses were measured by $\mathrm{N}_{1}-\mathrm{P}_{2}$ Event-Related Potentials (ERP) in response to auditory changes in frequency and intensity. Reactions to daily sounds were measured by the hyperacusis questionnaire. Correlations between AASP, hyperacusis questionnaire, and ERP were measured. Results: The basic ability to detect a change in stimuli manifested in $\mathrm{N}_{1}$ waveform was not significantly different. However, participants with hypersensitivity presented a stronger $\mathrm{P}_{2}$ response and a higher hyperacusis score. Daily expressions of auditory hypersensitivity correlated ( $p=0.05-p=0.01)$ with larger ERP responses. Conclusions: Auditory hypersensitivity as reflected in daily scenarios is evident in neurophysiological manifestations measured by ERPs. Understanding the relationship between the neural mechanisms of auditory hypersensitivity and its daily expressions, may optimize participation and wellbeing for people with hypersensitivity.
\end{abstract}

\section{Keywords}

Sensory Hypersensitivity, Hyperacusis, Event-Related Potentials (ERP), Daily Life, Adult 


\section{Introduction}

Individuals with sensory hypersensitivity have a distinct physiological and neural reactivity that manifests in hyper-excitability and over-reactivity to sensory stimuli [1] [2] [3]. This may affect function and participation in daily life activities [4] [5]. According to Dunn [6] the role and effect of sensory processing on peoples' daily life is generated from studying sensory processing from many perspectives. This study aimed to measure the neurophysiological responses to sound in adults with sensory hypersensitivity compared to those without hypersensitivity, from the neurophysiological perspective, using neurophysiological measurements and correlate these manifestations to the behavioral responses of daily life perspective.

\section{Sensory Processing and Sensory Processing Disorders (SPD)}

Sensory processing involves the reception of a physical stimulus, transduction of the stimulus into a neural impulse, perception of the conscious experience of the sensation as well as creating a behavioral responses to sensory input [1] [6].

Sensory Processing Disorders (SPD) may include hyper- or hypo-sensitivity as expressed in extreme behavioral responses to sensory stimuli, due to difficulties in balancing sensitivity (identification of novel or changing stimuli) or habituation (adjusting to familiar or ongoing stimuli) [7].

Dunn [8] proposed a model in which sensory processing depends upon: 1) neurological threshold (level of stimulation needed to respond to sensory stimuli), and 2) behavioral response strategy (active or passive) to this threshold. A high threshold combined with a passive response is classified as "low registration of stimuli". A high threshold combined with an active response is classified as "sensory seeking", in that the individual actively pursues intense sensory stimulation. A low threshold combined with a passive response is classified as "sensory sensitivity", whereas a low threshold combined with an active response is classified as "sensory aversion" in which the individual actively avoids sensory experiences [6]. According to Dunn the interaction between neurological threshold and behavioral response forms a continuum, the edges of which represent the four sensory processing patterns mentioned above. People with extreme sensory processing patterns may experience functional as well as emotional and cognitive difficulties in dealing with their daily environment, which negatively impact performance and social relationships [9].

Studies have established a link between SPD and atypical CNS processing. Individuals with sensory hypersensitivity were found to have a distinct physiological and neural reactivity that manifests in hyper-excitability and over-reactivity to sensory stimuli [1] [2] [3] [10]. These studies validated that individuals with SPD have distinct physiological, neural, electrodermal, and vagal tone differences, as compared to typical individuals.

The impact of these sensory processing experiences, on daily performances, function and participation in daily life activities, was emphasized in the literature along the years and across life span. Several studies showed a gradual wor- 
sening of sensory processing throughout the adult life span, which begin in middle age and continue in old age. For instance, older adults were found to be less responsive to startling auditory stimuli [11] and less responsive to uncomfortable temperatures compared with younger adults [12]. A decline in the main sensory modalities also noted in touch sensation among elderly participants [13]. When studied among 245 adults 18 - 86 years of age, performance in sensory processing of auditory tactile visual, and global sensory modalities were found to be significantly worse among middle age participants than of young adults and significantly better than that of older adults. [14].

Engel-Yeger, Hus, \& Rosenblum, [15] examine sensory processing among 118 healthy, independently functioning adults, in four age groups: 31 - 45, 46 - 60, 61 - 75 and 76+ years. They found that age significantly predicted sensory-processing abilities, as presented in all four patterns (Low Registration, Sensation Seeking, Sensory Sensitivity and Sensation Avoiding). Older people showed lower sensory-processing abilities then younger ones, mainly manifested in sensory seeking and low registration patterns. These correlations were attributed to a manifestation of degenerative processes of the sensory organs, tracts and of the brain ability to process sensory information [13].

SPD may limit participation, decrease social skills, impair friendships and relationships, self-confidence and self-esteem affect the interaction with the physical and human environments and cause the person to withdrawal from specific daily activities, that includes choice of clothing, where they go and with whom they relate emotionally, type and choice of a person's activities and also on their interpersonal relationships [1] [16] [17] [18] [19]. SPD also, negatively impact the ability to parent, work, or engage in home management, social, and leisure activities [20]. Since sensory processing affects participation, therefore, if significant correlations were found between sensory hypersensitivity as measured by the adult/adolescents sensory profile (AASP) and neural responses, as measured by event-related potentials (ERPs), then a link between daily life experiences and neural mechanisms related to hypersensitivity could be established, supporting the evidence from both subjective and objective perspectives.

One common trait of sensory hypersensitivity reported by children as well as adults with sensory hypersensitivity, with or without other co-morbidities, is auditory hypersensitivity [5] [21] [22]. Auditory hypersensitivity consists of a reported marked intolerance to ordinary environmental sounds while hearing thresholds are quite often normal. It is commonly used to describe the situation of a person who reports that sounds which would be acceptable to most normal hearing people are extremely loud or uncomfortable [23]. The current view of auditory hypersensitivity states that it is not only a subjective trait, but rather that the hypersensitivity arises from within the auditory system, either peripheral or central [24].

Therefore, research which combines the basic and applied science of neural reactivity and the daily performance of individuals with hypersensitivity may help substantiate the behavioral phenotypes of sensory hypersensitivity and re- 
fine the definition of sensory hypersensitivity, in addition to traditional behavioral definitions. Thus, it may improve assessment and intervention programs to raise performance and quality of life for people with sensory hypersensitivity.

Using Event-Related Potentials (ERPs) for studying auditory processing

Event-Related Potentials (ERPs) to auditory stimuli reflect activation of structure in the CNS and measure timing, magnitude and anatomic location of auditory processing and a spatio-temporal window into the processing of the auditory system [25]. Thus, ERPs provide an important bridge in studying the relationship between behavioral performance and brain activity [26]. In general, ERPs can be divided into two major categories: sensory (auditory) evoked potentials (such as $\mathrm{P}_{1}-\mathrm{N}_{1}-\mathrm{P}_{2}$ ), and processing-contingent potentials (MMN; $\mathrm{N}_{2} \mathrm{~b}-\mathrm{P}_{3} \mathrm{~b} ; \mathrm{P}_{300} ; \mathrm{N}_{400} ; \mathrm{P}_{600}$ ). Components are believed to be associated with sensory or cognitive information processing and are often measured by their amplitude and latency [26]. Latency is a time interval between stimulus onset and response [27] and amplitude is "The maximum extent of a vibration or oscillation, measured from the position of equilibrium" and is directly related to the intensity of a sound. [https://en.oxforddictionaries.com/definition/amplitude]

Auditory perception as a reflection of sensory processing can be expressed by the ability to detect changes in different sound dimensions, such as frequency and intensity. Natural sounds in the environment, such as speech and music, are complex acoustic signals that involve changes in intensity and frequency [27]. Therefore, abnormalities in amplitudes and latencies of ERPs in response to changes in frequency and intensity may contribute to the understanding of extreme behaviors related to sensory hypersensitivity in daily life [28].

ERPs technology was employed to examine auditory processing in individuals with hypersensitivity [4] [25] [29] [30] [31]. When using ERPs paradigms to measure sensory gating (the ability of the CNS to inhibit responses to redundant or irrelevant sensory stimuli) in response to paired auditory stimuli (two clicks), individuals with hypersensitivity exhibited less efficient sensory gating (i.e., lower suppression of auditory ERP $\mathrm{P}_{50}$ and $\mathrm{N}_{1}$ components) [29]. Decreased $\mathrm{P}_{50}$ responses were correlated with perceptual modulation difficulties (feelings of being flooded by sounds), whereas decreased $\mathrm{N}_{1}$ responses were correlated with an inability to filter out background sounds. The $\mathrm{N}_{1}$ has been suggested to reflect the basic ability to detect an acoustic change in the environment, whereas, the $\mathrm{P}_{2}$ is associated with early stages of stimulus evaluation and responses to the stimulus, including perceived affective attributes [32].

To successfully cope with the ever-changing environmental conditions of everyday life, people must quickly process external events [32]. The $\mathrm{N}_{1}-\mathrm{P}_{2}$ complex is associated with detection of the onset of a perceived stimulus, and can be evoked by an abrupt change in the perceived auditory environment. Dynamically changing intensity is an environmentally important cue for guiding locomotion and anticipating the arrival of a sound source. A change of intensity without a change in frequency may signal a slower moving object or vocal features, such as emphasis or affect in vocal communications [27] [33]. Changes of frequency 
represent a new auditory object in the scene or a marked change in an existing object, such as the Doppler Effect, due to fast motion toward or away from the listener, or a meaningful communication or warning call [33].

When comparing response to stimuli differing in intensity and frequency, measures of $\mathrm{N}_{1}-\mathrm{P}_{2}-\mathrm{N}_{2}-\mathrm{P}_{3}$ children with hypersensitivity displayed the most disorganization in their patterns of brain activity to auditory stimuli compared to typical children and adults [25]. Gavin et al. [4] also found different brain activity in children with hypersensitivity who demonstrated significantly smaller $\mathrm{P}_{300}$ amplitudes and shorter $\mathrm{N}_{200}$ latencies than typically developing children. They suggested that children with hypersensitivity are not able to dismiss a sensory experience with early attention and detection, and continue to process the information for much longer and more intensely. These brain activities correctly distinguished children with hypersensitivity from children who were typically developing and adults with $77 \%-90.5 \%$ accuracy.

Analyzing the responsiveness of the auditory system by using ERPs may provide a window to better understanding of the underlying mechanisms of extreme sensory processing and their behavioral and functional expressions. This information may assist in creating intervention programs that will be tailored to the person's unique sensory characteristics and needs in relation to real life experiences.

The purpose of this study was to compare neurophysiological responses to auditory inputs in adults with sensory hypersensitivity to those of typical controls and to correlate their neurophysiological responses and reactivity to auditory stimuli in daily life.

Hypotheses. 1) Participants with sensory hypersensitivity will show significantly larger neurophysiological manifestations to changes in sound intensity and frequency than typical controls, as measured in amplitude and latency of ERP components $\mathrm{N}_{1}$ and $\mathrm{P}_{2}$;2) Participants with sensory hypersensitivity will have significantly exaggerated behavioral auditory responses in daily life than typical controls; 3) Significant correlations will be found between the ERPs components and auditory hypersensitivity, as expressed in daily life scenarios.

\section{Materials and Method}

\subsection{Participants}

Twenty-seven right handed healthy participants, 18 - 40 years old, were recruited by advertisement that invited participation in a study on sensory processing. They were matched by age and gender and assigned according to their cut-off score in the Sensory Sensitivity or Sensation Avoiding quadrants of the AASP [34] as part of the diagnostic procedure. According to AASP norms, those who received a score above 42 in the "Sensory sensitivity" quadrant or a score above 43 in "Sensation avoiding" quadrants were assigned to the hypersensitivity group. Those who received scores that ranged from 26, 27 to 41 (indicating normative sensory performance) were assigned to the control group. 
The seeking and low registration quadrants of the AASP were not used as criteria for group affiliation, although most of the study participants in both groups were in the normative range in these quadrants. All the participants had bilateral normal hearing across $250-8000 \mathrm{~Hz}$ (equal to or less than $20 \mathrm{~dB} \mathrm{HL}$ ) measured by pure-tone audiometry and plotted on an audiogram according to the recommended procedure of the American Speech-Hearing Association (ASHA) [35].

Exclusion criteria: People with reported neurological conditions such as Attention Deficit Hyperactivity Disorder (ADHD), auditory impairments, history of head injuries, chronic diseases or learning disabilities were excluded from the study. Table 1 summarizes the participants' socio-demographic information. No significant differences were found between the groups in their socio-demographic variables.

\subsection{Instruments}

ADHD questionnaire. The ADHD questionnaire is retrieved from the Diagnostic and Statistical Manual of Mental Disorders (DSM-IV) [36]. This self-report questionnaire served for approving participant's inclusion criteria in this study. The questionnaire consists of 18 items divided into two categories: inattentive symptoms (9 items) and hyperactive-impulsive symptoms (9 items). Each item can receive either a positive or a negative answer. A clinical screening of ADHD requires six symptoms of either inattention or hyperactivity-impulsivity during the six months before the interview.

Table 1. Participants' socio-demographic information.

\begin{tabular}{|c|c|c|c|}
\hline Variable & & $\begin{array}{l}\text { Hypersensitivity group } \\
(\mathrm{n}=17) \\
\text { Mean (SD) }\end{array}$ & $\begin{array}{l}\text { Control group } \\
\quad(n=17) \\
\text { Mean (SD) }\end{array}$ \\
\hline Age & & $26.14(5.39)$ & $26.11(4.04)$ \\
\hline \multirow[t]{2}{*}{ Gender } & Male & $4(23.5 \%)$ & $4(23.5 \%)$ \\
\hline & Female & $13(76.5 \%)$ & $13(76.5 \%)$ \\
\hline \multirow[t]{4}{*}{ Education } & High-school & $5(29 \%)$ & $9(52.9 \%)$ \\
\hline & Non-Academic & $2(11.8 \%)$ & $1(5.9 \%)$ \\
\hline & B.A. & $6(35.3 \%)$ & $7(41.2 \%)$ \\
\hline & M.A. or higher & $3(17.6 \%)$ & $1(5.9 \%)$ \\
\hline \multirow[t]{2}{*}{ Income } & Low & $3(21.4 \%)$ & $5(35.7 \%)$ \\
\hline & High & $11(78.6 \%)$ & $9(64.3 \%)$ \\
\hline \multirow[t]{4}{*}{ Occupation } & University Student & $7(43.8 \%)$ & $14(82.4 \%)$ \\
\hline & Employee & $6(37.5 \%)$ & $3(17.6 \%)$ \\
\hline & Self Employed & $1(6.3 \%)$ & $0(0 \%)$ \\
\hline & High-school Student & $2(12.5 \%)$ & $0(0 \%)$ \\
\hline
\end{tabular}


Adolescent/Adult Sensory Profile (AASP). The AASP [34] The AASP is a self-reported measure of behavioral responses to sensory events in everyday life. Four scores are calculated for each of the quadrants presented in Dunn's model: sensation seeking, sensation avoiding, sensory sensitivity and low registration. For each quadrant, the participant's answers are divided according to five categories of "much less than most people"; "less than most people"; "similar to most people"; "more than most people"; and "much more than most people". In the sensory sensitivity quadrant, the resultant score for the "more than most people" and for "much more than most people" ranges from 42 to 75 . The resultant score for the sensation avoiding quadrant in these categories ranges from 43 to 75 . The resultant score for the "similar to most people" ranges from 26, 27 to 41 . The Hebrew version of the AASP presented good internal consistency for each of the AASP quadrants [37].

Hyperacusis questionnaire [38]. This questionnaire evaluates auditory hypersensitivity as expressed in daily life scenarios, measure whether the participant suffers from hyperacusis, and provides a detailed description of the symptoms. Scoring-14 self-rating items are included. Answers to each question/item is given on a 4-point scale, ranging from "no" (scoring 0 points), "yes, a little" (scoring 1 point), "yes, quite a lot" (scoring 2 points) to "yes, a lot" (scoring 3 points). The hyperacusis questionnaire is highly sensitive in discriminating participants in the general population. The results demonstrate the existence of an attentional dimension (questions 1 - 4 inclusive); a social dimension (questions 5 - 10 inclusive), and an emotional dimension (questions 11 - 14 inclusive). Statistical analyses show the three dimensions have satisfactory internal consistency reliability according to Cronbach's alpha values and factorial validity [39].

ERP procedure and measurement. The ERP recording and analysis was carried out with signal processing software of "Orgil Medical Equipments" Ltd. Participants were seated on a recliner in a sound attenuating, shielded room with an observation window (IAC, UK). During the recording, participants were asked to read a given book and ignore the auditory stimuli. The recording sites were based on the 10 - 20 system [39] using a custom-made cap. EEG was recorded from 21 channels, located at FP1-FP2-F3-FZ-F4-F7-F8 (frontal left-central-right), C3-Cz-C4 (central left-central-right), P3-PZ-P4 (parietal left-central-right), T3-T4-T5-T6 (temporal left -right), O1-O2 (occipital left-right) and A1-A2 (earlobes left-right) scalp sites. Electrode resistance was maintained at $<5 \mathrm{k}^{\prime} \Omega$. Eye blinks and movements (EOG) were monitored with an electrode placed below the right eye referenced to $\mathrm{Fz}$ [40]. All electrodes were referred to the middle of the chin. The ground electrode was placed on the right earlobe. Potentials from the EEG $(\times 100,000)$ and EOG $(\times 20,000)$ channels were amplified, digitized with a 12 -bit A/D converter at a rate of 256 samples/sec, filtered (0.1 to $100 \mathrm{~Hz}, 6 \mathrm{~dB}$ /octave slopes), and stored for off-line analysis. EEG processing began with segmentation of the continuous EEG to epochs, beginning $200 \mathrm{~ms}$ before until $1000 \mathrm{~ms}$ after stimuli onset. Four types of change to binaural stimuli were used. The protocol was based on a former study [34] and 
adjusted to the present one based on a pilot study. The stimuli were presented separately through ER•3A Insert Earphones. Changes occurred 1300 milliseconds post stimulus onset ( 1 or 1.3 second in duration) and were randomly selected in the series of stimuli from four types: 1) large increase in frequency from $250 \mathrm{~Hz}$ to $375 \mathrm{~Hz}$; 2) small increase in frequency from $250 \mathrm{~Hz}$ to $275 \mathrm{~Hz}$; 3) large increase in intensity of $8 \mathrm{~dB}$ from the $60 \mathrm{~dB}$ intensity at onset; and 4) small increase in intensity of $2 \mathrm{~dB}$ from the original $60 \mathrm{~dB}$ intensity at onset. The duration of each stimulus was either 3.3 or 3.0 seconds from onset to offset (Appendix). Each stimulus was randomly presented 150 times to avoid habituation to stimuli. The interval between stimuli was 500 or 700 milliseconds. ERP data analysis included eye movement correction based on the algorithm of correlations between the diagonal electro-oculogram (EOG) channel and each of the EEG channels [41] and artifact rejection $( \pm 150 \mu \mathrm{V})$ followed by segmentation. Average waveforms were then computed separately for each stimulus change type. These averages were computed for each subject as well as across subjects to obtain grand mean waveforms. ERP analysis included comparisons of $\mathrm{N}_{1}$ and $\mathrm{P}_{2}$ peak latencies and amplitudes, in response to the change-either intensity or frequency increases. Analysis of the EEG records was carried out with Beat Per Minute (BPM) signal processing software regarding FZ, CZ and PZ electrodes. Latencies of the $\mathrm{N}_{1}$ and $\mathrm{P}_{2}$ peaks were automatically derived using a partially automatic peak detection algorithm, which was overseen by an independent expert. Peaks were measured for each subject in each channel. Latencies of $\mathrm{N}_{1}$ were identified as the first negative peak elicited between $60 \mathrm{~ms}$ and $170 \mathrm{~ms}$ after the change. Latencies of the $\mathrm{P}_{2}$ were identified as the second positive peak elicited between $120 \mathrm{~ms}$ and $250 \mathrm{~ms}$ after the change. Differences in the effects of change on component $\mathrm{N}_{1}$ between participants in the hypersensitivity group and the control group were measured by the ratio between responses to small changes and large changes, in frequency and in intensity changes, separately. Amplitude differences of component $\mathrm{P}_{2}$ were measured by peak-to-peak evaluation of amplitude, in response to changes in frequencies and in response to changes in intensities. Recordings that were too noisy to produce a clear response were not statistically analyzed. Thus, different numbers of participants contributed to each test condition.

\subsection{Procedures}

The study was approved by the IRB of the University (no. 049/06). All the participants who complied with the inclusion criteria were invited to the Clinical Center at the University of Haifa. All the participants provided informed written consent. The procedure lasted up to 4 hours with breaks according to the participant's request. All participants were paid for their participation.

\section{Data analysis}

All numerical data were examined to assure normal distribution using the Kolmogorov-Smirnov test. Since normal distribution was found, one-way ANOVA and T-tests with Bonferroni correction were conducted to analyze the 
demographic data, the hyperacusis questionnaire and the AASP subscales. Repeated measures ANOVA was conducted to measure differences between the groups in amplitudes and latencies of $\mathrm{N}_{1}-\mathrm{P}_{2}$ in response to intensity and frequency changes. Pearson correlation examined the significance of correlations between the sensory profile scores, hyperacusis questionnaire and the ERP components $\mathrm{N}_{1}-\mathrm{P}_{2}$. The level of significance was set at $p \leq 0.05$.

\section{Results}

ERP manifestations of sensory hypersensitivity-differences in ERP components $\mathrm{N}_{1}$ and $\mathrm{P}_{2}$ between groups

No significant differences were found between the groups regarding latencies and amplitudes of $\mathrm{N}_{1}$ in response to changes in frequency and intensity. However, participants with hypersensitivity had significantly longer $\mathrm{P}_{2}$ latencies than controls, in response to large changes in frequency $(250 \mathrm{~Hz}$ to $375 \mathrm{~Hz})[\mathrm{F}(2,40)$ $\left.=4.55, p=0.01, \mu^{2}=0.18\right]$. Participants with hypersensitivity also had consistently longer $\mathrm{P}_{2}$ latencies than controls, in response to small changes in frequency $(250 \mathrm{~Hz}$ to $275 \mathrm{~Hz})$ and in response to large change in intensity $(60 \mathrm{~dB}+8$ $\mathrm{dB}$ ), yet these differences did not reach statistical significance.

Manifestations of sensory hypersensitivity in daily life as reflected in self reports

Table 2 presents the means of the AASP scores and the frequency of participants found in each sensory processing performance range in each group. As evident from Table 2 , the hypersensitive groups scored significantly higher than controls in Sensory sensitivity $(p<0.05)$ and Sensation avoiding $(p<0.01)$ AASP quadrants.

Hyperacusis score in the hypersensitivity group was significantly higher $(\mathrm{M}=$ $35.50, \mathrm{Med}=37.00, \mathrm{SD}=8.14)$ than the control group $(\mathrm{M}=22.64$, Med $=22.64$, $\mathrm{SD}=5.33) \mathrm{t}=5.392, p<0.01$. In the general sample, Sensory sensitivity AASP scores and Sensation avoiding AASP scores were significantly correlated with the total hyperacusis score $(\mathrm{r}=0.75, p<0.001, \mathrm{r}=0.71, p<0.001$, respectively).

Correlations between the objective and subjective measures of sensory hypersensitivity in the total sample

As can be evident in Table 3, higher sensory sensitivity and sensation avoiding were found in the auditory processing items, measured by the AASP, and greater hyperacusis complaints, measured by the hyperacusis questionnaire, were found and were significantly correlated with larger responses to both large frequency and large intensity changes, as measured by latency and amplitudes of $\mathrm{N}_{1}$ and $\mathrm{P}_{2}$.

\section{Discussion}

This is one of the first studies to examine the relationship between neurophysiological manifestations of responses to auditory stimuli in adults with sensory hypersensitivity and their daily life expressions. According to our results, participants 
Table 2. Means of AASP scores and frequency of participants found in each sensory processing performance range, in each group.

\begin{tabular}{|c|c|c|c|c|c|c|c|c|c|}
\hline & & \multicolumn{3}{|c|}{ AASP Norms } & \multicolumn{2}{|c|}{$\begin{array}{l}\text { Hypersensitivity } \\
\text { group }\end{array}$} & \multicolumn{2}{|c|}{ Control group } & \multirow[t]{2}{*}{$\mathbf{F}$} \\
\hline & & Range & $\mathrm{N}$ & Actual range & Mean $\pm(S D)$ & $\mathrm{N}$ & Actual range & Mean $\pm(\mathrm{SD})$ & \\
\hline \multirow{3}{*}{$\begin{array}{l}\text { Low } \\
\text { registration }\end{array}$} & Under norm & $15-23$ & 3 & $21-23$ & $22.00(1.00)$ & 4 & $16-22$ & $20.00(2.70)$ & $F(1,26)=3.16 \mathrm{NS}$ \\
\hline & Norm & $24-35$ & 6 & $29-35$ & $32.00(2.75)$ & 10 & $26-34$ & $30.20(2.82)$ & \\
\hline & Above norm & $36-75$ & 4 & $36-39$ & $37.00(1.41)$ & 0 & & & \\
\hline \multirow[t]{3}{*}{ Seeking } & Under norm & $15-42$ & 5 & $35-42$ & $38.60(2.70)$ & 3 & $41-42$ & $41.66(.57)$ & $F(1,26)=6.95^{\star *}$ \\
\hline & Norm & $43-56$ & 8 & $43-48$ & $46.25(1.75)$ & 10 & $45-54$ & $49.00(2.94)$ & \\
\hline & Above norm & $57-75$ & 0 & & & 1 & 60 & $60.00(60.00)$ & \\
\hline \multirow{3}{*}{$\begin{array}{c}\text { Sensory } \\
\text { sensitivity }\end{array}$} & Under norm & $15-25$ & 0 & & & 2 & $23-24$ & $23.50(.70)$ & $F(1,26)=60.25^{\star *}$ \\
\hline & Norm & $26-41$ & 0 & & & 12 & $26-40$ & $35.00(4.15)$ & \\
\hline & Above norm & $42-75$ & 13 & $43-53$ & $47.53(3.47)$ & 0 & & & $F(1,26)=21 \cdot 29^{\star}$ \\
\hline \multirow[t]{3}{*}{$\begin{array}{c}\text { Sensory } \\
\text { avoidance }\end{array}$} & Under norm & $15-26$ & 0 & & & 1 & 26 & $26.00(26.00)$ & \\
\hline & Norm & $27-41$ & 4 & $31-41$ & $36.50(5.25)$ & 13 & $28-40$ & $34.30(4.69)$ & \\
\hline & Above norm & $42-75$ & 9 & $42-52$ & $47.44(3.64)$ & 0 & & & \\
\hline
\end{tabular}

${ }^{*} p<0.05 ;{ }^{* *} p<0.01, \mathrm{SD}=$ standard deviation.

Table 3. Correlations between the sensory profile, hyperacusis questionnaire and ERP components $\mathrm{N}_{1}-\mathrm{P}_{2}$, among the entire Sample.

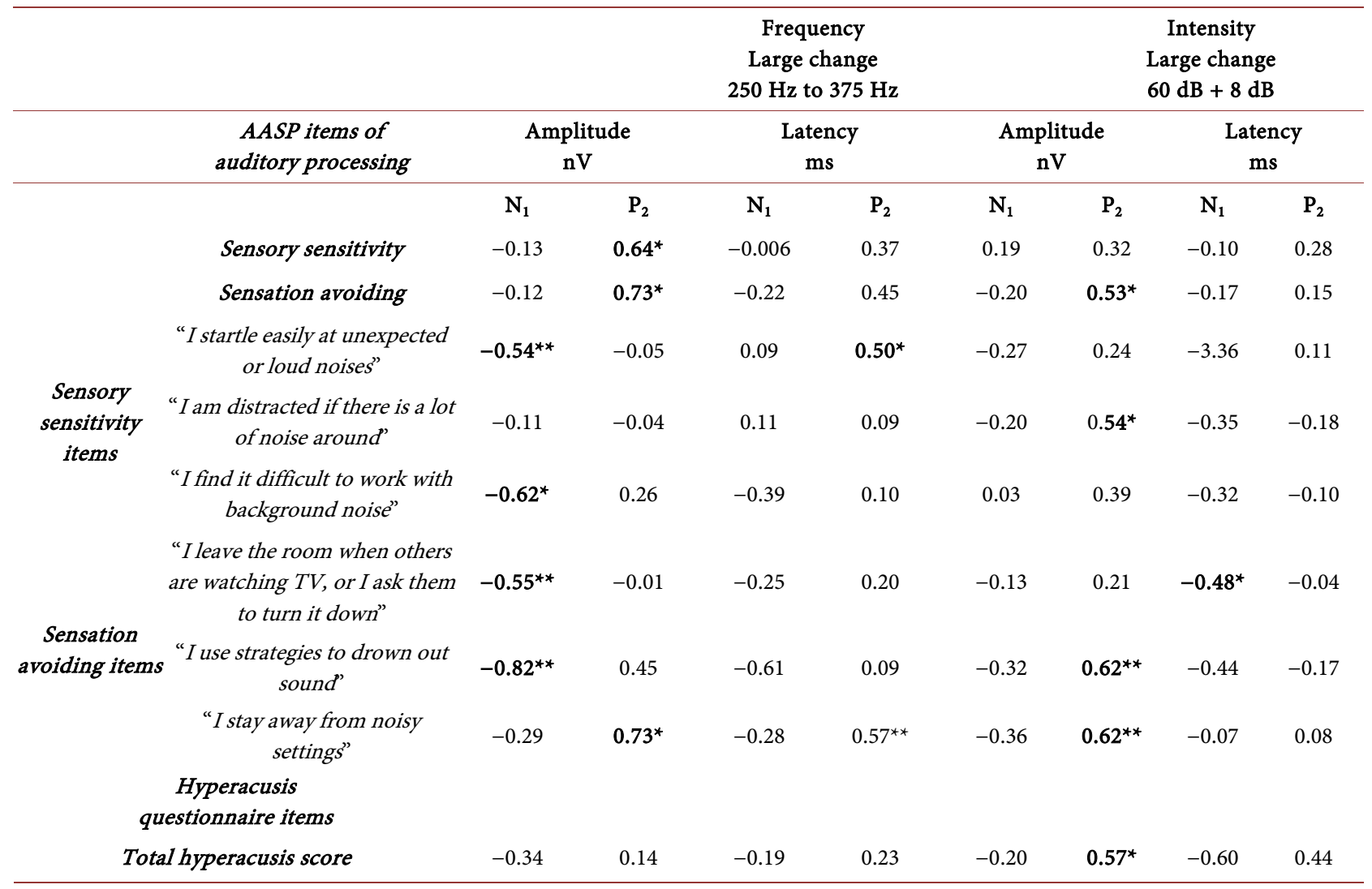




\section{Continued}

\begin{tabular}{|c|c|c|c|c|c|c|c|c|}
\hline $\begin{array}{c}\text { "Do you have trouble reading in a noisy or loud } \\
\text { environment?" }\end{array}$ & $-0.70^{*}$ & 0.27 & -0.22 & -0.24 & -0.08 & 0.14 & -0.59 & -0.07 \\
\hline $\begin{array}{l}\text { Do you have difficulty listening to conversations } \\
\text { in noisy places? }\end{array}$ & -0.51 & $0.60^{*}$ & -0.85 & 0.22 & -0.22 & 0.38 & -0.20 & 0.42 \\
\hline $\begin{array}{c}\text { "Do you find the noise unpleasant in certain } \\
\text { social situations (e.g. night clubs, pubs or bars, } \\
\text { concerts, firework displays, cocktail } \\
\text { receptions)?" }\end{array}$ & $-0.74^{\star *}$ & 0.30 & -0.36 & -0.06 & -0.23 & $0.65^{* *}$ & -0.15 & 0.18 \\
\hline $\begin{array}{c}\text { "Do you ever turn down an invitation or not go } \\
\text { out because of the noise you would have to } \\
\text { face?" }\end{array}$ & 0.04 & $0.65^{*}$ & 0.20 & 0.42 & 0.74 & 0.39 & 0.84 & 0.34 \\
\hline $\begin{array}{c}\text { "Do noises or particular sounds bother you } \\
\text { more in a quiet place than in a slightly noisy } \\
\text { room?" }\end{array}$ & -0.15 & 0.22 & 0.10 & 0.39 & -0.28 & $0.70^{* *}$ & 0.11 & 0.27 \\
\hline
\end{tabular}

${ }^{\star} p<0.05 ;{ }^{* *} p<0.01, \mathrm{~ms}=$ milliseconds, $\mathrm{nV}=$ nano-volt.

with hypersensitivity reported greater auditory sensitivity expressed in hyperacusis in daily situations, compared to typical controls.

The differences between both groups were also manifested in different ERPs, as measured by $\mathrm{P}_{2}$ Latency in response to a large change in frequency. The $\mathrm{P}_{2}$ wave reflects the process of stimulus evaluation [32] and is associated with perceptual analysis and attentional allocation [42]. The prolonged $\mathrm{P}_{2}$ latency among the hypersensitive group indicates the longer time required for perceptual analysis [42]. In daily life, this may lead to allocating more attention to sensory stimuli, which may accompany the overwhelming, uncomfortable sensory experience, and may account for functional difficulties in daily life, reported by adults with hypersensitivity [43].

In the present study, such uncomfortable sensory experiences were noted in the responses to the hyperacusis questionnaire. Participants who indicated that they are more troubled with social and leisure activities, for instance, in relation to the questions "Do you find the noise unpleasant in certain social situations (e.g. night clubs, pubs or bars, concerts, firework displays, cocktail receptions)?" and "Do you ever turn down an invitation or not go out because of the noise you would have to face?" had significantly greater ERP responses, as can be evident in Table 3. These correlations may reflect a limitation in participating in social and leisure activities.

Also, indicated in Table 3, it was found that among the entire sample, the sensory sensitivity and sensation avoiding scores of all sensory modalities, and especially in relation to the auditory items, were significantly correlated with the ERP responses. Hence, the more sensitive or more avoiding was the behavior, the larger were the amplitudes of $\mathrm{N}_{1}$ and $\mathrm{P}_{2}$, and the more prolonged were the latencies. This may reflect the greater attentional resources needed to process the details of a change [43] among people with sensitive and avoiding patterns.

Dunn [8] claimed that individuals with sensory avoidance limit sensory opportunities because they have difficulties in perceiving, organizing and respond- 
ing to unfamiliar sensory inputs that may be perceived as "threatening". The positive strong correlations that were found between the AASP measures of both sensory sensitivity and sensation avoiding in all the sensory modalities with the hyperacusis complaints, measured by the hyperacusis questionnaire, support Dunn's claim, and the relationship between neural mechanisms and behavioral measurements of hypersensitivity.

Interestingly, both groups did not differ significantly in $\mathrm{N}_{1}$ measures According to Nishihara et al. [44], $\mathrm{N}_{1}$ reflects the basic ability to detect whether changes in the environment have accrued. Thus, $\mathrm{N}_{1}$ reflects a change-detection system; a memory-based comparison process, in which amplitude and latency are dependent on the physical attributes of a difference between standard and deviant sounds [44]. In the present study, any change, either in intensity or in frequency, as reflected in $\mathrm{N}_{1}$ was noticed by the participants in both groups at approximately the same latency or magnitude (amplitude response). This basic ability to detect whether changes in the environment have accrued was not significantly different between the groups. Support for this finding can be found in a study conducted by Bar-Shalita et al. [45] and in Bar-Shalita et al. [10], demonstrating that sensory hypersensitivity does not imply lowered sensory thresholds, (i.e. the ability to identify a stimulus change). Our results suggest that people with hypersensitivity have a similar ability to detect stimuli as typical people, however, as indicated by the later component $\mathrm{P}_{2}$, people with hypersensitivity have larger responses when perceiving the stimuli and responding to their affective attributes. This may explain the emotional hyper-arousability frequently reported among people with sensory hypersensitivity [46].

\section{Limitations and Future Studies}

This study referred only to patterns of hypersensitivity and was based on a relatively small sample of typical adults. Since the stimuli were somewhat moderate, as were the differences between them, this together with the small sample might account for the inability to reach statistical significance in all the tested conditions. The correlations and differences found in the present study should be further examined on larger samples of individuals' extreme sensory processing patterns and illuminate the relationship between the underlying neural mechanisms of sensory hypersensitivity and the person's coping with daily life demands. Also, further studies, on larger sample sizes across larger age range, with hyposensitive as well as hypersensitive patterns, and on populations with special conditions, are recommended.

\section{Conclusions}

The study has added to current knowledge by describing the underlying neurophysiological mechanisms of auditory hypersensitivity and their daily life expressions. The correlations and differences found in the present study may indicate that daily life expressions of auditory hypersensitivity are supported by 
neurophysiological manifestations and may explain the unique experience that adults with hypersensitivity frequently experience in daily life, in compare to those who have typical sensory processing patterns.

The correlation between daily life experience of auditory hypersensitivity and their neurophysiological manifestation may improve evaluation and intervention for people with extreme sensory processing patterns that interfere with their daily life performance and routine.

\section{Implications for clinical practice}

In 2001, the World Health Organization (WHO) emphasized the need for universally applicable classification and assessment tools, both for activity levels and overall levels of participation and roles of social life for people who are limited in their activity due to disease, impairment, disability, handicap or disorder; such one is SPD and specifically sensory hypersensitivity.

Thus, understanding the relationship between neural mechanisms, behavioral and participation in daily life, may enable a better diagnosis of sensory processing patterns and, may focus intervention on the person's specific needs in a real-life context. This may assist the person with sensory hypersensitivity and his/her family to better cope with sensory challenges in behavioral aspects and environmental adaptations, all of which may optimize meaningful participation in daily life and well-being. We recommend that by elevating people's awareness to their special sensory processing patterns, their neural origin, their functional expressions, clinicians together with the person can enable the development of strategies to better cope with daily sensory challenges, optimize the person's participation in daily life and elevate wellbeing.

\section{Acknowledgements}

We wish to thank all the participants who participated in this study.

\section{References}

[1] Ahn, R.R., Miller, L.J., Milberger, S. and McIntosh, D.N. (2004) Prevalence of Parents' Perceptions of Sensory Processing Disorders among Kindergarten Children. The American Journal of Occupational Therapy, 58, 287-293. https://doi.org/10.5014/ajot.58.3.287

[2] Bar-Shalita, T., Vatine, J.-J., Parush, S., Deutsch, L. and Seltzer, Z. (2012) Psychophysical Correlates in Adults with Sensory Modulation Disorder. Disability and Rehabilitation, 34, 943-950. https://doi.org/10.3109/09638288.2011.629711

[3] Schaaf, R.C., et al. (2010) Parasympathetic Functions in Children with Sensory Processing Disorder. Frontiers in Integrative Neuroscience, 4, 4. https://doi.org/10.3389/fnint.2010.00004

[4] Gavin, W.J., Dotseth, A., Roush, K.K., Smith, C.A., Spain, H.D. and Davies, P.L. (2011) Electroencephalography in Children with and without Sensory Processing Disorders during Auditory Perception. The American Journal of Occupational Therapy, 65, 370-377. https://doi.org/10.5014/ajot.2011.002055

[5] James, K., Miller, L.J., Schaaf, R., Nielsen, D.M. and Schoen, S.A. (2011) Phenotypes within Sensory Modulation Dysfunction. Comprehensive Psychiatry, 52, 715-724. 
https://doi.org/10.1016/j.comppsych.2010.11.010

[6] Dunn, W. (2001) The Sensations of Everyday Life: Empirical, Theoretical, and Pragmatic Considerations. The American Journal of Occupational Therapy, 55, 608-620. https://doi.org/10.5014/ajot.55.6.608

[7] McIntosh, D.N., Miller, L.J., Shyu, V. and Hagerman, R.J. (1999) Sensory-Modulation Disruption, Electrodermal Responses, and Functional Behaviors. Developmental Medicine \& Child Neurology, 41, 608-615. https://doi.org/10.1017/S0012162299001267

[8] Dunn, W. (1997) The Impact of Sensory Processing Abilities on the Daily Lives of Young Children and Their Families: A Conceptual Model. Infants \& Young Children, 9, 23-35. https://doi.org/10.1097/00001163-199704000-00005

[9] Engel-Yeger, B. and Dunn, W. (2011) Exploring the Relationship between Affect and Sensory Processing Patterns in Adults. British Journal of Occupational Therapy, 74, 456-464. https://doi.org/10.4276/030802211X13182481841868

[10] Bar-Shalita, T., Vatine, J.-J., Yarnitsky, D., Parush, S. and Weissman-Fogel, I. (2014) Atypical Central Pain Processing in Sensory Modulation Disorder: Absence of Temporal Summation and Higher After-Sensation. Experimental Brain Research, 232, 587-595. https://doi.org/10.1007/s00221-013-3767-y

[11] Ford, J.M., Roth, W.T., Isaacks, B.G., White, P.M., Hood, S.H. and Pfefferbaum, A. (1995) Elderly Men and Women Are Less Responsive to Startling Noises: N1, P3 and Blink Evidence. Biological Psychology, 39, 57-80.

https://doi.org/10.1016/0301-0511(94)00959-2

[12] Taylor, N.A.S., Allsopp, N.K. and Parkes, D.G. (1995) Preferred Room Temperature of Young vs. Aged Males: The Influence of Thermal Sensation, Thermal Comfort, and Affect. The Journals of Gerontology. Series A, Biological Sciences and Medical Sciences, 50A, M216-M221.

[13] Wickremaratchi, M.M. and Llewelyn, J.G. (2006) Effects of Ageing on Touch. Postgraduate Medical Journal, 82, 301-304.

[14] Humes, L.E. (2015) Age-Related Changes in Cognitive and Sensory Processing: Focus on Middle-Aged Adults. American Journal of Audiology, 24, 94-97. https://doi.org/10.1044/2015_AJA-14-0063

[15] Engel-Yeger, B., Hus, S. and Rosenblum, S. (2012) Age Effects on Sensory-Processing Abilities and Their Impact on Handwriting. Canadian Journal of Occupational Therapy, 79, 264-274. https://doi.org/10.2182/CJOT.2012.79.5.2

[16] Kinnealey, M., Oliver, B. and Wilbarger, P. (1995) A Phenomenological Study of Sensory Defensiveness in Adults. The American Journal of Occupational Therapy, 49, 444-451. https://doi.org/10.5014/ajot.49.5.444

[17] Kinnealey, M., Koenig, K.P. and Smith, S. (2011) Relationships between Sensory Modulation and Social Supports and Health-Related Quality of Life. The American Journal of Occupational Therapy, 65, 320-327. https://doi.org/10.5014/ajot.2011.001370

[18] Engel-Yeger, B. and Ziv-On, D. (2011) The Relationship between Sensory Processing Difficulties and Leisure Activity Preference of Children with Different Types of ADHD. Research in Developmental Disabilities, 32, 1154-1162. https://doi.org/10.1016/j.ridd.2011.01.008

[19] Dunn, W., Little, L., Dean, E., Robertson, S. and Evans, B. (2016) The State of the Science on Sensory Factors and Their Impact on Daily Life for Children. OTJR: Occupation, Participation and Health, 36, 3S-26S. 
[20] May-Benson, T.A., Otrl, S. and Kinnealey, M. (2012) An Approach to Assessment of and Intervention for Adults With Sensory Processing Disorders.

[21] Van Hulle, C.A., Schmidt, N.L. and Goldsmith, H.H. (2012) Is Sensory Over-Responsivity Distinguishable from Childhood Behavior Problems? A Phenotypic and Genetic Analysis. Journal of Child Psychology and Psychiatry, 53, 64-72. https://doi.org/10.1111/j.1469-7610.2011.02432.x

[22] Gothelf, D., Farber, N., Raveh, E., Apter, A. and Attias, J. (2006) Hyperacusis in Williams Syndrome: Characteristics and Associated Neuroaudiologic Abnormalities. Neurology, 66, 390-395. https://doi.org/10.1212/01.wnl.0000196643.35395.5f

[23] Blaesing, L. and Kroener-Herwig, B. (2012) Self-Reported and Behavioral Sound Avoidance in Tinnitus and Hyperacusis Subjects, and Association with Anxiety Ratings. International Journal of Audiology, 51, 611-617. https://doi.org/10.3109/14992027.2012.664290

[24] Katz, J., Chasin, M., English, K., Hood, L.J. and Tillery, K.L. (2014) Handbook of Clinical Audiology. 7th Edition, Lippincott Williams \& Wilkins, Philadelphia.

[25] Davies, P.L., Chang, W.-P. and Gavin, W.J. (2010) Middle and Late Latency ERP Components Discriminate between Adults, Typical Children, and Children with Sensory Processing Disorders. Frontiers in Integrative Neuroscience, 4, 16. https://doi.org/10.3389/fnint.2010.00016

[26] Michael, M.J., Aminoff, J. and Daroff, R.B. (2014) Encyclopedia of the Neurological Sciences. 2nd Edition, Elsevier, Amsterdam.

[27] Soeta, Y. and Nakagawa, S. (2012) Auditory Evoked Responses in Human Auditory Cortex to the Variation of Sound Intensity in an Ongoing Tone. Hearing Research, 287, 67-75. https://doi.org/10.1016/j.heares.2012.03.006

[28] Banaschewski, T. and Brandeis, D. (2007) Annotation: What Electrical Brain Activity Tells Us about Brain Function That Other Techniques Cannot Tell Us-A Child Psychiatric Perspective. Journal of Child Psychology and Psychiatry, 48, 415-435. https://doi.org/10.1111/j.1469-7610.2006.01681.x

[29] Kisley, M.A., et al. (2006) Gamma and Beta Neural Activity Evoked during a Sensory Gating Paradigm: Effects of Auditory, Somatosensory and Cross-Modal Stimulation. Clinical Neurophysiology, 117, 2549-2563.

https://doi.org/10.1016/j.clinph.2006.08.003

[30] Davies, P.L. and Gavin, W.J. (2007) Validating the Diagnosis of Sensory Processing Disorders Using EEG Technology. The American Journal of Occupational Therapy, 61, 176-189. https://doi.org/10.5014/ajot.61.2.176

[31] Brett-Green, B.A., Miller, L.J., Schoen, S.A. and Nielsen, D.M. (2010) An Exploratory Event-Related Potential Study of Multisensory Integration in Sensory Over-Responsive Children. Brain Research, 1321, 67-77. https://doi.org/10.1016/j.brainres.2010.01.043

[32] Tremblay, K.L. and Burkard, R.F. (2012) Translational Perspectives in Auditory Neuroscience. Plural Publishing, Oxford.

[33] Dimitrijevic, A., Lolli, B., Michalewski, H.J., Pratt, H., Zeng, F.G. and Starr, A. (2009) Intensity Changes in a Continuous Tone: Auditory Cortical Potentials Comparison with Frequency Changes. Clinical Neurophysiology, 120, 374-383. https://doi.org/10.1016/j.clinph.2008.11.009

[34] Brown, C., Tollefson, N., Dunn, W., Cromwell, R. and Filion, D. (2001) The Adult Sensory Profile: Measuring Patterns of Sensory Processing. The American Journal of Occupational Therapy, 55, 75-82. https://doi.org/10.5014/ajot.55.1.75 
[35] ASHA Practice Policy (2005) Guidelines for Manual Pure-Tone Threshold Audiometry.

[36] American Psychiatric Association (1994) DSM-IV: Diagnostic and Statistical Manual of Mental Disorders. 4th Edition, American Psychiatric Association, Washington DC.

[37] Engel-Yeger, B. (2012) Validating the Adolescent/Adult Sensory Profile and Examining Its Ability to Screen Sensory Processing Difficulties among Israeli People. British Journal of Occupational Therapy, 75, 321-329. https://doi.org/10.4276/030802212X13418284515839

[38] Khalfa, S., Dubal, S., Veuillet, E., Perez-Diaz, F., Jouvent, R. and Collet, L. (2002) Psychometric Normalization of a Hyperacusis Questionnaire. Journal for Oto-Rhino-Laryngology and Its Related Specialties, 64, 436-442. https://doi.org/10.1159/000067570

[39] Jasper, H. (1958) The Ten Twenty Electrode System of the International Federation. Electroencephalography and Clinical Neurophysiology, 10, 371-375.

[40] Light, G.A., et al. (2010) Electroencephalography (EEG) and Event-Related Potentials (ERPs) with Human Participants. In: Current Protocols in Neuroscience, Chapter 6, John Wiley \& Sons, Inc., Hoboken, 1-24. https://doi.org/10.1002/0471142301.ns0625s52

[41] Attias, J., Urbach, D., Gold, S. and Shemesh, Z. (1993) Auditory Event Related Potentials in Chronic Tinnitus Patients with Noise Induced Hearing Loss. Hearing Research, 71, 106-113. https://doi.org/10.1016/0378-5955(93)90026-W

[42] Yang, J., Guan, L., Dedovic, K., Qi, M. and Zhang, Q. (2012) The Neural Correlates of Implicit Self-Relevant Processing in Low Self-Esteem: An ERP Study. Brain Research, 1471, 75-80. https://doi.org/10.1016/j.brainres.2012.06.033

[43] Tremblay, K.L., Shahin, A.J., Picton, T. and Ross, B. (2009) Auditory Training Alters the Physiological Detection of Stimulus-Specific Cues in Humans. Clinical Neurophysiology, 120, 128-135. https://doi.org/10.1016/j.clinph.2008.10.005

[44] Nishihara, M., Inui, K., Motomura, E., Otsuru, N., Ushida, T. and Kakigi, R. (2011) Auditory N1 as a Change-Related Automatic Response. Neuroscience Research, 71, 145-148. https://doi.org/10.1016/j.neures.2011.07.004

[45] Bar-Shalita, T., Vatine, J.J., Seltzer, Z. and Parush, S. (2009) Psychophysical Correlates in Children with Sensory Modulation Disorder (SMD). Physiology \& Behavior, 98, 631-639. https://doi.org/10.1016/j.physbeh.2009.09.020

[46] Engel-Yeger, B. and Dunn, W. (2011) The Relationship between Sensory Processing Difficulties and Anxiety Level of Healthy Adults. British Journal of Occupational Therapy, 74, 210-216. https://doi.org/10.4276/030802211X13046730116407 


\section{Appendix}

ERP protocol, based on Dimitrijevic et al. (2009) [33].

Changes occurred 1300 milliseconds post stimulus onset and were randomly selected in the series of stimuli from four types of changes ( 1 or 1.3 second in duration):

1) A large increase in frequency from $250 \mathrm{~Hz}$ to $375 \mathrm{~Hz}$.

2) A small increase in frequency from $250 \mathrm{~Hz}$ to $275 \mathrm{~Hz}$.

3) A large increase in intensity of $8 \mathrm{~dB}$ from the $60 \mathrm{~dB}$ intensity at onset.

4) A small increase in intensity of $2 \mathrm{~dB}$ from the $60 \mathrm{~dB}$ intensity at onset.

- Each stimulus was either 3.3 or 3.0 seconds in duration from onset to off-set

- Each stimulus was randomly presented 150 times

- The Inter Stimulus Interval (ISI) was 500 or 700 milliseconds 